\title{
On Application Value of Applied Mathematics in Modern Economic Management
}

\author{
Ran Zheng ${ }^{1, a}$ \\ ${ }^{1}$ Muir College, University of California, 9500 Gilman Dr. La Jolla, CA 92093, the United State \\ araz016@ucsd.edu \\ *Corresponding author: Ran Zheng
}

Keywords: Modern economic management, applied mathematics, application value

\begin{abstract}
Nowadays, China is in a new stage of rapid economic development. In the face of the ever-changing modern society, how to maintain China's current economic development and to promote China's economic transformation and upgrading is extremely important. With the continuous advancement of China's economic construction, the requirements for modern economic management are also gradually increasing. Modern economic management includes not only the internal control and management of the enterprise, but also the state macro-control of economic construction. Only by giving full play to the important role of modern economic management can we ensure the smooth operation of China's modern economic development and meet the objective requirements of current economic construction. This paper is a brief introduction to the application value of applied mathematics in modern economic management.
\end{abstract}

\section{Introduction}

At present, China's economic development and construction is in a critical period of deepening reform. With the continuous improvement of economic development, people's requirements for economic development have also increased. In order to meet fully the current evolving economic development situation, only by constantly adjusting and upgrading can we truly adapt to the current development of the times, and can truly meet the objective requirements of deepening reform for economic development and construction. Applied mathematics is the most closely related discipline with economics. With its unique mathematical logic, it adjusts the current objective situation of economic development through its constant influence on the economy. It can analyze objectively and effectively the current state of economic development through mathematical logic, presenting the economic development situation intuitively. Besides, it can also reflect the development situation of different economic entities to a certain extent, satisfying the mathematical requirements for the analysis of economic development in the current economic management process. Moreover, it can promote the economic system reform and development in a certain sense.

\section{Overview of Applied Mathematics}

Applied mathematics is a discipline that continuously enriches and perfects the mathematical theoretical knowledge system and finally applies it to practice through the study of mathematical knowledge methods. The applied mathematics design is extensive, not only including various types of knowledge in mathematical theory to a certain extent, such as differential equations, mathematical logic, etc., but also incorporating the mathematical problems that arise in the application process into the category of applied mathematics. Applied mathematics is divided into two aspects: "application" and "mathematics", and links "application" and "mathematics" through corresponding links, thus forming a discipline that is consistent with practical applications, and truly meeting objective requirements for the current discipline development. For applied mathematics, its development can not only integrate mathematics into the real life to a certain extent, so that mathematics knowledge can be transformed into easy-to-understand application knowledge 
in a certain way, but also play its irreplaceable important role in other fields such as economic management, according with the current state of economic development in the true sense.

Compared with pure mathematics, the application characteristics of applied mathematics are extremely prominent. Applied mathematics is different from pure mathematics. Pure mathematics is a theoretical discipline that is more academic relatively. It mainly focuses on the internal relations of mathematics and mathematical theoretical knowledge, with development aims at itself. Applied mathematics belongs to a kind of mathematics mainly based on applicability. Its research object is not only in the mathematics discipline itself, but also in applying mathematical knowledge to various fields through research application of mathematics. The economic field is a very important aspect. On the one hand, applied mathematics can be applied to the real life by continuously adjusting and upgrading the mathematical knowledge with a higher application degree. On the other hand, it satisfies the objective requirements of current economic development to a certain extent, combining mathematics and modern society development in the true sense, truly breaking the application limitations of the original pure mathematics to a certain extent and promoting the development of mathematics.

\section{Application Value of Applied Mathematics in Modern Economic Management}

\subsection{Adjusting and Controlling the Quantitative Relation of Economic Activities}

In the process of modern economic management, in the face of the ever-changing market information environment, how to grasp fully the development direction in economic development is extremely important. With the continuous adjustment of China's economic development situation, the role of economic management in economic development has become more and more significant. The application of applied mathematics in modern economic management can adjust and control the quantitative relation of economic activities to a certain extent. On the one hand, through reasonable numerical theory analysis, it has a clear understanding of the number of different economic activities in the market, and can make a sound economic development plan according to mathematical knowledge. On the other hand, the market economy activity disorder caused by the limitations of the market economy is avoided in a certain sense. In this way, it can not only maintain the status quo of the original economic development but also fully grasp the economic development trend, which truly meets the current economic development trend and achieves a high level of economic management to a certain extent.

\subsection{Analyzing and Clarifying the Quantitative Relation}

Modern economic management is a multi-agent and multi-faceted management system, which includes not only economic regulation at the national macro level, but also internal economic management of market entities. For the development of enterprises, the economic management of enterprises affects not only the development prospects of the enterprises themselves, but also the overall trend of the competitive environment in the whole market in a certain sense. The application of applied mathematics in enterprise economic management can meet the management requirements of enterprises for mathematical aspects to the maximum extent, have a clear analysis and grasp of the internal economic activities of the enterprise to a certain extent, and really combine the corresponding economic activities within the enterprise through the analysis and clarity of the quantitative relation. This way on the one hand reduces the internal waste of resources and truly realizes sensible resource allocation. On the other hand, it also has a clear understanding of the business situation of enterprise economy in a certain sense, according with the current requirements of internal management of enterprises and promoting the enterprise's long-term development.

\subsection{Promoting Economic Entities to Further Deepen Reform}

The objective application of applied mathematics in modern economic management is an important embodiment of the combination of current disciplines and practice. With the continuous development and improvement of the current socialist market economy, the theoretical knowledge 
required for modern economic management has also increased. Applied mathematics as an extremely applied mathematics discipline plays an irreplaceable role in the current economic development process. Applying applied mathematics to the process of modern economic management has promoted economic entities to deepen further reforms to a certain extent, enabling enterprises to adapt truly to the trend of economic development under the ever-changing trend of economic development. Such a way has maximized the combination of modern market economy subjects and theoretical knowledge of economic development, allowing economic entities to make full use of mathematical knowledge to solve economic development problems in the process of deepening reform, really realizing the practical application of mathematical knowledge and promoting the reform and development of economic entities.

\section{The Concrete Application of Applied Mathematics in Modern Economic Management}

\subsection{Collecting and Processing Economic Management Information Timely and Accurately}

With the continuous improvement of the modern social market economic system, China's economic development speed is gradually accelerating. In the face of the evolving modern economic society, how to carry out reasonable and effective modern economic management is extremely important. The application of applied mathematics in modern economic management can not only help the enterprise to adjust and upgrade, but also promote the optimal development of the economic situation. On the one hand, applied mathematics can collect and process relevant economic management information timely, with the characteristic of timeliness. On the other hand, it can also adjust and analyze the objective information needed for economic management, with the characteristic of accuracy. In this way, not only can it have a targeted grasp of economic management information to a certain extent, satisfying the objective conditions of current economic development in a true sense, but also can rationally analyze and plan economic management information, promoting objective development of economic management and providing data and information conditions able to be relied on for modern economic management.

\subsection{Basing actual economic forecasts and helping to make decisions}

Nowadays, with the continuous acceleration of China's comprehensively deepening reform process, people are paying more and more attention to the important role of economic management in economic development. As an extremely applied discipline, applied mathematics not only has strong research value, but also always occupies an irreplaceable important position in the application field. The important application of applied mathematics in modern economic management is to adjust economic development based on actual economic forecasts and to make decisions based on actual forecasts. In this way, the analytical advantages of applied mathematics are developed fully in the true sense, meeting the pre-requirements of current economic management. Making decision through actual forecasts not only reduces management errors caused by improper decision-making, but also avoids mistakes caused by blind decision-making in a certain sense, truly conforming to the objective situation of current economic development, breaking the traditional way of decision-making and promoting the improvement of modern economic management.

At present, with the continuous improvement of the practical application level of disciplines, the application requirements of economic development for different disciplines are gradually increasing. For modern economic management, only integrating rational logic knowledge can truly meet the objective requirements of current economic development. The rational application of applied mathematics in modern economic management promotes the comprehensive balance of all aspects through formulating economic plans. It integrates the various factors needed in the current economic management process by unique mathematical logic knowledge of applied mathematics. Only in this way can we truly grasp the direction of economic development and then be able to adjust various types of subjects in the market to maximize the comprehensive balance. This way not only promotes the improvement of economic management level to a certain extent, but also 
improves the management efficiency of modern economic management. On the other hand, it embodies the important application of applied mathematics in different fields and truly achieves the combination of theory and practice.

\subsection{Arranging Production Reasonably and Realizing Scientific Management of the Enterprise}

At this stage, since the reform and opening up, with the continuous improvement of economic development, the modern market economy has shown a booming status quo. Due to the relatively low barriers to entry in the modern market, the number of enterprises in the market is relatively large. In order to have a unique competitive advantage, the requirements for modern economic management are also increasing. The application of applied mathematics in modern enterprise economic management achieves scientific management of enterprises through reasonable arrangement of production. Besides, it fully mobilizes the various elements required for enterprise production by the professional theoretical knowledge of applied mathematics. Moreover, it communicates different aspects of enterprise management through certain adjustments, achieving scientific management in the true sense. Only in this way can we ensure that enterprises can have a clear market position in the process of economic management so that they can analyze the real market demand, find their own position in the fierce market competition and promote the long-term development of enterprises.

\section{Conclusion}

Applied mathematics is a discipline based on mathematical analysis. With the gradual changes in the economic development situation, the requirements for the influence of applied mathematics in economic management are also increasing. Applied mathematics can not only use the unique subject knowledge of mathematics to analyze the status quo of economic development to a certain extent, but also finally grasp the potential development direction of economic development and objectively grasp the economy. Applied mathematics is applied to modern economic management according with the current objective situation of economic development, maximizing the advantages of disciplines, breaking the conventional economic management methods, providing a valuable experience for the long-term development of China's economic management, really serving the modernization and promoting the improvement of the economic level.

\section{References}

[1] Feng Guoyong. Research on the Integration of Economic Applied Mathematics and Accounting Major Teaching in Higher Vocational Colleges Based on the Combination of Engineering and Learning[J]. Journal of Jilin Radio and Television University, 2017(02): 95-96+127.

[2] Sun Shaoping. The Design of Economic Applied Mathematics Course Based on Systematization of Work Process_- Taking the Logistics Management Major of Higher Vocational Education as an Example[J]. Occupation, 2016(11): 88-89.

[3] Yin Ming, Zhu Xiaolin, Guo Qingwei. Research and Practice on the Feature Specialty Construction of Mathematics and Applied Mathematic_-Taking Hefei University of Technology as an Example[J]. University Mathematics, 2015, 31(06): 38-44.

[4] Xiong Mei, Zhang Dalin, Yan Zhongquan. Exploration of the Training Mode of Mathematics and Applied Mathematics Talents in Local Universities under the Vision of Transformation Development[J]. Journal of Qiannan Normal College for Nationalities, 2015, 35(06): 52-55.

[5] Bai Xiu, Yang Peifeng. Strengthening the Construction of Mathematics and Applied Mathematics Majors Based on the Need of Social Economy and Science and Technology Development[J]. Inner Mongolia Science and Technology and Economy, 2014(02): 23-24. 
[6] Zhang Haiyong, Li Qinghong. Research on the Positioning and Curriculum Setting of Mathematics and Applied Mathematics Majors in Applied Undergraduate Colleges[J]. Journal of Chengdu University of Technology, 2013, 16(04): 95-97.

[7] Fan Hongjun, Liu Bin. Discussion on the Combination of Economic Applied Mathematics and Accounting Major Teaching in Higher Vocational Colleges Based on the Combination of Engineering and Learning[J]. China Township Enterprise Accounting, 2011(11): 193-194.

[8] Zhang Liqian. On the Development of Applied Mathematics_-Strengthening the Connection of Mathematics and Academic Style(First Half)[J]. Mathematical Statistics and Management, 2001(03): 1-9. 